\title{
Health:
}

http://hea.sagepub.com/

\section{The experience of mental distress and recovery among people involved with} the service user/survivor movement

Carolina S Chassot and Felismina Mendes

Health (London) published online 14 October 2014

DOI: $10.1177 / 1363459314554313$

The online version of this article can be found at:

http://hea.sagepub.com/content/early/2014/10/14/1363459314554313

Published by:

๑SAGE

http://www.sagepublications.com

Additional services and information for Health: can be found at:

Email Alerts: http://hea.sagepub.com/cgi/alerts

Subscriptions: http://hea.sagepub.com/subscriptions

Reprints: http://www.sagepub.com/journalsReprints.nav

Permissions: http://www.sagepub.com/journalsPermissions.nav

Citations: http://hea.sagepub.com/content/early/2014/10/14/1363459314554313.refs.html

>> OnlineFirst Version of Record - Oct 14, 2014

What is This? 


\title{
The experience of mental distress and recovery among people involved with the service user/survivor movement
}

\section{Carolina S Chassot}

University of Évora, Portugal; École des Hautes Études en Sciences Sociales, France

\section{Felismina Mendes}

University of Évora, Portugal; Centre for Research and Studies in Sociology, University Institute of Lisbon (CIES-IUL), Portugal

\begin{abstract}
This article examines how the personal experiences of mental distress of people involved in the British service user/survivor movement were shaped or transformed by this involvement, and the impact of involvement on their recovery journeys. The analysis was based on 12 in-depth interviews with service users/survivors who are, or were once, involved with the service user/survivor movement. Three large themes were identified regarding the ways in which social movement involvement affected the personal experience of mental distress: (a) making sense and reframing mental distress, (b) the social experience of involvement and (c) identity and identity reconstruction. We discuss how some features of the service user/survivor movement, such as selfhelp, user involvement, the centrality of experience to collective action, and the range of political positions adopted by activists can affect experience and recovery in different forms. As an exploratory study that looks into a complex topic, our findings illuminate the ways of surviving, recovering and experiencing mental distress in the context of a significant social movement.
\end{abstract}

\section{Keywords}

mental distress, mental health, recovery, service user/survivor movement

\section{Corresponding author:}

Carolina S Chassot, Universidade Federal do Rio Grande do Sul - Instituto de Psicologia, Rua Ramiro Barcelos, 2600, sala 300k, Porto Alegre, RS 90035-003, Brazil.

Email: carolchassot@gmail.com 


\section{Introduction}

In this article, we aim to examine the subjective experiences of mental distress of people who are, or were once, actively involved in the British service user/survivor movement. With this exploratory study, we hope to contribute to the understanding of how these experiences were shaped or transformed by this involvement, and the effects of involvement on participants' recovery journeys.

\section{The British service user/survivor movement}

In the 1970s and 1980s, a distinct social movement led by people who have experienced some form of mental distress and who have been through the mental health-care system developed in the United Kingdom (Crossley, 2006; Rogers and Pilgrim, 1991). At first a 'patient' movement, it was later renamed a 'service user' or 'survivor movement', accounting for different identity claims and moments within the process of mobilisation. Here, we use the umbrella term 'service user/survivor (movement)', a solution that may lose in precision, in view of the diversity of the movement, but acknowledges the lack of agreement in terminology (Rose and Beresford, 2009).

This social movement is enacted by informal groups or formal organisations led by service users/survivors, who promote their individual and collective rights, voicing their views about the psychiatric system and creating alternatives to mainstream mental health-care services, such as support groups or user-led services. The main types of activities developed by service user/survivor groups, according to Wallcraft et al. (2003) are: self-help and social support (79\%), consulting with decision makers or 'user involvement' $(72 \%)$, education and training $(69 \%)$, creative activities $(41 \%)$, campaigning (38\%), advocacy (36\%) and provide a service other than advocacy (28\%).

Early groups, such as the Mental Patients Union (MPU) and Campaign Against Psychiatric Oppression (CAPO), strongly opposed psychiatry's theory and practices, each adopting a somewhat cohesive stance to affirm their political beliefs. In the 1980s and early 1990s, Survivors Speak Out (SSO) and the UK Advocacy Network (UKAN) shifted focus compared to earlier groups - not only because they represented the emergence of a 'survivor' culture within the movement, but also because they displayed a new interest in plurality, including activists who held various political positions and views towards psychiatry (Crossley, 2006).

Throughout the 1990s, the British survivor movement grew rapidly. While in 1985 there were about a dozen groups, in 2005 there were at least 500, or possibly more (Campbell, 2005). One of the main drives for this expansion was consumerist policies created since the 1980s, particularly the 1990 National Health Service (NHS) and Community Care Act, which made consultation with service users a requirement for community care planning (Campbell, 2005; Wallcraft et al., 2003).

On one hand, this demand for user involvement created opportunities for service users to provide input and achieve the changes they expected to see in mental health services. On the other hand, groups increasingly worked in partnership with the mental health system and relied on state funding, which has made it more difficult for them to keep an independent, critical position as compared to earlier groups (Crossley, 2006; Wallcraft 
et al., 2003). Despite the current challenges, the movement is facing, the British service user/survivor movement has been an important collective actor that has helped reshape the field of psychiatric contention in the United Kingdom (Crossley, 2006).

\section{The experience of mental distress}

We understand the subjective experience of mental distress not simply as the direct experience of psychiatric symptoms, but as a complex phenomenon, composed of several different aspects, including the person's cognitive, sensory and emotional experience; how their social experience is affected by mental distress, including changes in their social behaviour and in other people's responses and behaviours towards them; their experience in mental health services; their identity and self-perception regarding mental distress; and the meanings they create and adopt to explain their own experiences. The subjective experience of mental distress is shaped not only by individual, biological and interpersonal circumstances, but also culturally, spatially and historically, by a number of social actors and their interplay, one of them being social movements.

This experience has been silenced until recently. In the mental health literature, service users are almost always portrayed 'as objects of the clinical gaze of mental health professionals' (Rogers and Pilgrim, 2005: 238), as their experiences are translated into the terms and concepts considered scientifically valid, while their own views and narratives are often treated with suspicion and regarded as irrational.

However, exceptions to this norm may be increasingly found. First-person accounts of mental distress experience published in scientific journals show a growing interest in the value of survivors' experiential knowledge (e.g. Deegan, 1988; Chadwick, 2007). Following this paradigmatic shift are qualitative studies of users' narratives that put the survivor/service user perspective at the centre of research and provide valuable insights into the experience of mental distress (e.g. Borg et al., 2011; Veseth et al., 2011). Participatory-action research in mental health (e.g. Hutchinson and Lovell, 2013) or survivor research (Sweeney et al., 2009) are other examples of this recent trend of valuing the expertise of service users and reclaiming academic research as a field of symbolic dispute.

The (international) service user/survivor movement played a major part in this shift of perspective, as promoting survivors' own narratives was an important strategy to overthrow professional symbolic power and reclaim their voice. One major influence of the service user/survivor movement in the mental health field was certainly the promotion of the 'recovery' vision, as it has become an important concept to reshape care practices.

The notion of recovery is shrouded in confusion and disputed meanings, as multiple actors use the same term in different contexts. One use of the term is attributed to a tradition of longitudinal clinical studies, which have found that symptom remission for individuals with severe mental illness was more common than previously believed. In this line of thought, recovery is conceptualised as total or partial cure, or as 'recovery from' mental illness (Davidson and Roe, 2007). This notion is firmly based on the biomedical model, as treatment remains the key determinant of recovery (Pilgrim, 2008).

A second approach to recovery places emphasis on rehabilitation, as symptoms become less important than the impairment they produce. Treatment no longer aims at symptom remission, but is conceptualised in terms of skills training to prevent relapses 
and maximise social integration. Professional intervention, however, still remains a central requirement for recovery (Pilgrim, 2008).

The final view, put forward by the service user/survivor movement, understands recovery as a process of overcoming the multiple invalidations service users have survived: the experiences that caused their impairments, the social invalidation of rejection and stigma, and the invalidation of professional action, such as objectifying diagnoses, detention without trial and iatrogenic treatments (Pilgrim, 2008). Therefore, professional interventions are no longer taken for granted, but critically questioned, while autonomy becomes an important aspiration. Moreover, recovery on these terms is more about a personal journey - one that cannot be reduced to a result of professional interventions. It involves regaining hope, taking responsible action for one's life, challenging other people's expectations, developing valued relationships and a new meaning for life (Deegan, 1988; Turner-Crowson and Wallcraft, 2002). However, while it is certainly personal, it is important to highlight that recovery is highly dependent on environmental conditions and social structure (Pilgrim, 2008), and therefore can be potentially reinforced by collective action.

It is in this latter sense that we frame recovery in this study. We do not limit the term to a product of professional interventions, but to a process that can take place in very different kinds of settings, one of them being the service user/survivor movement organisations and groups.

Despite this direct link between recovery and the service user movement, there is a paucity of studies directly concerned with the effects of service user activism on recovery or on personal experiences of mental distress. There are, however, some studies concerned with the effects of 'user involvement' and 'self help' - which are some of the activities that service user groups develop (Wallcraft et al., 2003) - and thus, may indirectly illuminate aspects of the service user/survivor movement.

The umbrella term 'user involvement' is commonly used to refer to the active participation of service users in mental health services and organisations. Nelson et al. (2001) found that user involvement in Canadian mental health services increased users' selfconfidence, control over daily life, independence of services, promoted greater community integration and the creation of positive identities. In the United Kingdom, Barnes and Bowl (2001) found that, at times, participation and consultation with mental health services tended to be detrimental to participants' own mental health. Service users reported not being able to contribute effectively to decisions, and usually felt patronised and unheard, showing that the effects of user involvement may depend more on how this involvement is actually developed than on its mere existence.

Composed of groups of peers who share a similar problem and come together for mutual assistance and support (Archibald, 2007), the self-help movement has been a major influence over service user/survivor movements in many countries. While the British service user/survivor movement cannot be reduced to a self-help movement, it has had a strong self-help component from the very beginning (Crossley, 2006). Literature reviews on mental health self-help practices have found limited but promising evidence that structured mutual support groups organised and composed by service users provide various benefits to participants' recovery and well-being (see Davidson et al., 1999; Pistrang et al., 2012). 
Informal peer support, such as personal relationships between service users, have also shown to be beneficial. Topor et al. (2009) note that friendships between service users and involvement with the service user movement itself are frequently referred to as important in recovery narratives, for they create environments in which service users feel accepted, and where they cannot only receive, but also give advice and offer help.

Somewhere between user involvement and self-help are the recent experiences of 'peer providers' or 'peer staff', in which people with mental distress experience are employed to provide some form of service to other peers. Literature reviews found that peer staff interventions often produce better outcomes than their non-peer counterparts, despite the significant challenges still involved in their implementation process. Studies also indicate that there may be some contributions to recovery that are specific to peer interventions, linked to the instillation of hope, role modelling and the use of empathy (Davidson et al., 2012; Walker and Bryant, 2013). Moran et al. (2012) have investigated the recovery benefits for peer providers themselves, and found the role improved foundational, emotional, spiritual, social and occupational wellness.

These studies address specific aspects of service user collective action (user involvement and self-help) and therefore collaborate with the understanding of the movement's effects on experience. They fail, however, to address an important aspect of this social movement, that is, political activism. Closest to this topic is Herman and Musolf's (1998) ethnographic study that focussed on resistance among ex-psychiatric patients in the United States and Canada. They found that among the various resistance strategies employed by ex-patients, political activism was the most central in providing a positive non-deviant identity, enhancing self-esteem and helping ex-users to find a new sense of purpose for their lives.

\section{Research methods}

Since a social movement is an informal entity characterised by a low degree of institutionalisation, without clearly defined boundaries and decision-making structures (Della Porta and Diani, 1999), recruiting individuals who are part of a social movement is a delicate task. We have decided to use organisations and formal groups as a channel to reach these individuals. Two national user-led organisations aided us in participant recruitment, sending invitations to their contact lists for the research. It should be clarified that the participants were not necessarily members of these organisations - they were part of their contact lists, but many were involved in different organisations than those two.

Approved by the Ethics Committee of the University of Évora in May 2011 (Document $\# 10039$ ), the research followed the principles of the Declaration of Helsinki for research with human beings.

There were two selection criteria for research participants: (a) current or previous experience of mental distress and use of mental health services and (b) self-identification as a member of the British service user/survivor movement. In August 2011, 12 in-depth interviews were conducted in six different locations in the United Kingdom, a point in which we assessed that data saturation was achieved and the information provided was reaching redundancy (Bogdan and Biklen, 1998; Streubert and Carpenter, 2011). 
Our participants were four males and eight females, aged 35-73 years (mean age = 52.75 years). The sample was very heterogeneous in terms of past experience of mental distress (ranging from mild to severe), socio-economic background and experience of services (most had been to psychiatric hospitals and/or therapeutic communities, while a small minority had relied only on primary and secondary care services, such as a treatment in psychiatric outpatient clinics continued by follow-up appointments with a general practitioner (GP)). Regarding movement involvement, there was also a great variability, as it can be seen in Table 1.

As the table shows, there is a balance of local and national activists, as well as between paid and voluntary participation. While it is difficult to label each participant's political orientation towards psychiatry and mainstream mental health services, it can be broadly stated that national activists, with longer careers and who performed paid work as service users, tended to be more critical to the notion of mental illness and mainstream psychiatry than locally involved, voluntary service users. This reflects the movement dynamics we have discussed previously.

It is important to note that the experiences of service users involved in the service user/ survivor movement may not be representative of the general population of mental health service users - they may have had more negative experiences in services, or hold more critical views towards psychiatry than most service users. As we are not interested in understanding the general experience of mental distress, but the effects of movement engagement on this experience, the particularity of our participants' experience is fully justified.

In semi-structured interviews, 90.5 minutes long on average (ranging from 47 to 120 minutes), participants were questioned in detail about their past experience of mental distress and mental health services, movement involvement and opinion about the effect of the latter on the former. With the participants' written consents, the interviews were recorded and transcribed. We analysed the transcriptions using thematic analysis (Braun and Clarke, 2006). In the coding process, we used an inductive, bottom-up approach to thematic analysis, inspired by grounded theory (Charmaz, 2006). Through this mixed approach, we aimed to produce codes very close to the data, which were then the basis for a more detailed analysis, focussed on our specific research questions.

From this analysis, three large themes were identified, regarding the ways in which social movement involvement affected the personal experience of mental distress: (a) making sense and reframing mental distress, (b) the social experience of movement involvement and (c) identity and identity reconstruction. In the following sections we will present each of the three themes from the data analysis. All three sections are punctuated by the most illustrative quotations from the participants' interviews.

\section{Making sense and reframing mental distress}

The first category is related to changes in the meanings attached to mental distress, assuming that these meanings are not given, but constructed and reconstructed by the actors immersed in social relations. The experience of mental distress was described as essentially painful and difficult, whether as an attribute of the experience itself (e.g. feeling sad, frightened, wanting to die) or as a later assessment of the experience (e.g. regretting something done during a crisis). Furthermore, the stigmatising cultural meanings of 
Table I. Characterisation of participants.

\begin{tabular}{|c|c|c|c|c|c|}
\hline Pseudonym & Gender & $\begin{array}{l}\text { Age } \\
\text { (years) }\end{array}$ & $\begin{array}{l}\text { Level of } \\
\text { activism }\end{array}$ & $\begin{array}{l}\text { Current or former roles in user- } \\
\text { led organisation and/or other } \\
\text { organisation (as service user) }\end{array}$ & $\begin{array}{l}\text { Type of } \\
\text { participation }\end{array}$ \\
\hline Adam & M & 40 & Local & $\begin{array}{l}\text { Service user representative with } \\
\text { mental health }(\mathrm{MH}) \text { provider }\end{array}$ & Voluntary \\
\hline Annie & $\mathrm{F}$ & 51 & Local & $\begin{array}{l}\text { Instructor in a recovery program/ } \\
\text { member of local user-led } \\
\text { organisation }\end{array}$ & $\begin{array}{l}\text { Paid and } \\
\text { voluntary }\end{array}$ \\
\hline Emma & $\mathrm{F}$ & 58 & National & $\begin{array}{l}\text { Service user consultant/chair } \\
\text { and member of national and } \\
\text { international user-led organisations }\end{array}$ & $\begin{array}{l}\text { Paid and } \\
\text { voluntary }\end{array}$ \\
\hline Gordon & $M$ & 73 & $\begin{array}{l}\text { National/ } \\
\text { local }\end{array}$ & $\begin{array}{l}\text { Advocate/member of national and } \\
\text { local user-led organisations }\end{array}$ & $\begin{array}{l}\text { Mostly } \\
\text { voluntary }\end{array}$ \\
\hline Harriet & $\mathrm{F}$ & 65 & National & $\begin{array}{l}\text { Service user consultant/member of } \\
\text { national user-led organisation }\end{array}$ & Mostly paid \\
\hline Karen & $F$ & 35 & National & $\begin{array}{l}\text { Service user researcher/consultant/ } \\
\text { representative with } \mathrm{MH} \text { provider }\end{array}$ & Mostly paid \\
\hline Marianne & $F$ & 62 & National & $\begin{array}{l}\text { Service user researcher/consultant/ } \\
\text { chair and member of national user- } \\
\text { led organisations }\end{array}$ & Mostly paid \\
\hline Ralph & M & 61 & Local & $\begin{array}{l}\text { Member of national user-led } \\
\text { organisation }\end{array}$ & Voluntary \\
\hline Roger & $M$ & 54 & Local & $\begin{array}{l}\text { Service user representative with } \\
\mathrm{MH} \text { provider/member of local } \\
\text { user-led organisation }\end{array}$ & Voluntary \\
\hline Rose & $\mathrm{F}$ & 52 & $\begin{array}{l}\text { National/ } \\
\text { local }\end{array}$ & $\begin{array}{l}\text { Service user consultant/researcher/ } \\
\text { advocate/founder of local user-led } \\
\text { organisation }\end{array}$ & $\begin{array}{l}\text { Paid and } \\
\text { voluntary }\end{array}$ \\
\hline Sally & $\mathrm{F}$ & 42 & Local & $\begin{array}{l}\text { Volunteer in resource centre/ } \\
\text { service user representative with } \\
\text { MH provider }\end{array}$ & Voluntary \\
\hline Valerie & $\mathrm{F}$ & 40 & National & $\begin{array}{l}\text { Service user researcher/writer/ } \\
\text { member of international user-led } \\
\text { organisation }\end{array}$ & Mostly paid \\
\hline
\end{tabular}

mental illness and psychiatric diagnosis give the experience of mental distress an utterly negative meaning, occasionally with devastating effects on the person's identity:

So my own [mental health problems], I saw them as a moral personal flaw. That I was a completely flawed individual, that I was useless, I was dysfunctional. [...] And also, the idea of me punishing myself, that's one little bit of why I started self harm. [...] It fitted with the concept of my problems as a completely flawed, inadequate human being. (Valerie)

Getting involved through a local group or national organisation puts service users in direct contact with other people who experience mental distress, or who have experienced 
it in the past. Participants felt that groups provided a safe environment for them to share their experiences, as even their most painful or embarrassing aspects were accepted and embraced by their peers without the negative moral judgements, which were frequent elsewhere:

And they've [service users] been people that I can talk to most easily. Cause within five minutes of meeting somebody at a conference or something, we can tell each other our life stories. [...] Being able to be honest about your personal experiences has been so liberating for me! [...] It's enabled me to be who I am and not have to deny who I am in my life. I can talk about my stepfather being a paedophile and people don't go: 'don't tell me that, that's horrible!' (laughter). (Marianne)

Taking into consideration their peers' welcoming attitudes, some participants have started to reassess the value of their experiences, which could then be reframed as neutral or even as positive experiences. It does not mean that service users have necessarily a greater capacity of empathy, but that they are more able to understand the aspects of experience related to mental distress because of their history - aspects that can be especially difficult to integrate and to disclose:

I suppose it's different bits of me are understood in different settings. And it's nice to have that part of me [experiencing mental distress and going to a therapeutic community] understood, as well as the more technical side, the side that enjoys crafts and all the rest of it. So it is complementary. (Annie)

Identifying oneself as a service user or survivor and getting involved with movement groups may be a form of using the experience of mental distress constructively, which may influence the personal process of making sense of experiences. Involvement may reinforce neutral or positive connotations for mental distress or mental illness, as opposed to a mostly negative meaning that they usually acquire:

Rather than just seeing myself as a person who was ill, I started slowly to conceive the idea that my experiences could be used in a positive way. [...] Actually my status as a service user was actually actively useful, in my job. [...] It was positive, it wasn't a negative thing at all. [...] I'd say that it definitely had an influence on how comfortable and confident I felt to be open about my own status and experiences. (Valerie)

Furthermore, the movement's groups and organisations serve as a repository of information, disseminating scientific knowledge as well as alternative explanations regarding mental distress. Service users who are dissatisfied with the available cultural and scientific explanations find in service user/survivor groups a support for their beliefs. This kind of support is especially important when service users' personal experiences and beliefs clash with the mainstream explanations about the nature of their problems and how they should be treated:

It was helpful to find other people like myself who've got some concerns about the psychiatric system and power imbalances, and a rather narrow drugs-based approach. Cause I know that 
[...] the standard psychiatric explanations just ... they wouldn't help me to make sense of it. And at the same time it didn't really seem to be much else within the standard system in this country. (Harriet)

Although alternative models of understanding mental distress are important to some members, we also found that other participants valued access to mainstream psychiatric information through service user/survivor groups, which they used to better understand their conditions and to negotiate care with practitioners. In this sense, groups that offer ample information and allow members to make their own informed decisions provide an important service for users who make sense of their experience without challenging the psychiatric model.

\section{The social experience of involvement}

Another aspect of the experience of mental distress is how it affects social relations. We found that participants had remarkably little support from the people in their lives. Almost all of them had families that were either unsupportive (mostly because they were confused and did not know how to deal with distress) or prejudicial (such as cases of violence and abuse). Another recurring aspect of this experience was feeling stigmatised and discriminated when disclosing psychiatric diagnosis to other people:

I play poker in the poker league, and I met two lovely ... married women there [...] they invited me around. And they said 'what do you do?', I said 'I'm in hospital'. They thought I worked there, and when I told them I was a mental patient, they refused to ... [They told them] 'don't let him come in'. I could have lied and said I was a worker, then I could have gone in and played poker. (Ralph)

Many participants were unemployed and had depended on disability benefits to make a living, at least at one point in their lives. The majority had very negative experiences in mental health services - a negative social experience that makes recovery more strenuous.

We have found that engaging in the service user/survivor movement changed service users' social experience in several ways. Being a part of a network of peers creates, for many service users, a sense of community and belonging, which may have beneficial effects, as isolation and stigma are important aspects of the social experience of mental distress:

I was the only one. Only one in the world. [... When I first met other service users I know now, other patients ... And from that moment my life just have been transformed fully for the better, beyond belief. [...] I've met the most incredible people with an array of different problems, different traumas, different types of fears and inabilities. We all had that one thing in common. We had been stigmatised, and let down by society. (Roger)

While this sense of community and belonging was overwhelmingly reported by participants, a few reported that peers could display an unwelcoming attitude when their legitimacy as a service user came into question. Those who fail to fit a certain 
profile - characterised by severe mental distress and treatment in psychiatric hospitals - were sometimes excluded and rejected by their peers:

To be seen by others as a grown member of the service user movement I think you'd have to be a hard core service user $[. .$.$] experienced maybe a psychotic breakdown, experienced treatment$ without your consent [...] So, I don't know if I would ever get seen as a part of the user movement. (Karen)

When identity references are too rigid, they may become excluding and divisive. All of this is transmitted in subtle ways, through what Karen called a 'principle of competition' for having the worst mental health problems.

Legitimacy to speak on behalf of service users may also be questioned by non-service user members. Many participants reported tokenistic attitudes by mental health professionals. When convenient, their words were sometimes reframed as being the words of someone who is unwell, with a disturbed rationality attributed to mental illness. Paradoxically, when service users are perceived by their opponents as being articulate and providing rationally constructed arguments, they are dismissed for not being representative of service users:

It can get messy in a sense that I am someone who still uses services, so I don't want [...] what I'm saying to be viewed as someone who's slightly unwell or 'this is the reason he's saying that'. It's truthful, it's open, and it's a genuine view of how I think people are feeling and what their needs are. [...] But sometimes it can be picked up in the wrong way [...] how it's interpreted gets me a little bit concerned. (Adam)

In user involvement activities, service users have to support their point of view and legitimacy in the face of more powerful opponents, and feel their input is hardly ever valued or taken into account. This combative context certainly has emotional effects on participants:

Although I do suppose it's something I want to do, but it [user involvement] can be quite high cost emotionally. [...] I suppose if I wanted an easy life I wouldn't be doing this at all (laughter). (Harriet)

On the other hand, getting involved provides service users/survivors a number of opportunities for employment, public action and social recognition - many of which are related to user involvement.

I had a really good life using my service user identity. It's enabled me to live well with a mental health condition for many years and earn a bit of money. And the thing is I couldn't get a job otherwise [...] I would struggle now to have a 'proper job', in inverted commas. (Emma)

Even when unpaid, service users can be presented with opportunities that may otherwise not be available. Participants reported that taking part in service user groups allowed them, among other things, to travel abroad for survivor conferences, speak in public, appear in the media and even meet The Queen. 
Getting involved with the movement on one hand seems to provide service users with a sense of community and belonging to a group, an affiliation that ultimately can expand their possibilities of action in the social sphere. It promotes inclusion through social recognition and flexible, rewarding jobs. On the other hand, it involves being exposed to confrontational relations, either external or internal, which may emphasise their disadvantages and affect them at a personal level. These can be damaging and disempowering experiences that may add distress and impact recovery.

\section{Identity and identity reconstruction}

Participants' experience of mental distress was inseparable from the negative meanings of mental illness, which often led to a negative impact upon personal identity. However, those who came in contact with discourses that challenged established notions of mental illness and inserted mental distress into a scenery of oppression and social control began to question stereotypes associated with mental illness.

Rose's story is the most illustrative of this theme, although it has also appeared in a number of interviews. She was already a politicised defender of black people's rights when she had her first psychotic crisis. The extreme nature of her mental distress affected her in a fundamental way, and it was hard for her to respond to stigmatising remarks, as she was remorseful and shameful about her history:

[After being discharged from psychiatric hospital] you feel ... well, you're traumatised again, and also you feel like a ... like a nobody! You feel lessened, [...] you feel worthless, because you think people just [scandalise] and then they treat you like they're scared, they scapegoat you, like everything that goes wrong, you're the one to blame. (Rose)

Engaging in survivor organisations provided her with an opportunity to reinsert her experience of mental distress in her previous frame of black peoples' activism against racism and discrimination:

I was empowered before, I lost it in hospital, I got it back again. [...] And I started to understand the politics, the bigger picture. [...] That African people were going through this. And it's a country-wide, it's a worldwide thing. [...] You're just supposed to [feel] even, be doped up, sedated, drugged up, calm, compliant, not asking questions. [...] That's not me. I never was and never will be. And because I'm a fighter and I'm not compliant, that's why I'm here where I am today. (Rose)

Rose started to question the way she was being treated by her family and mental health professionals. The beliefs she initially internalised as being true were questioned, and anger became motivation for political activism.

Vulnerability is another frequent attribute of people who experience mental distress, and it may become crystallised in the identity of the victim, as Roger's interview, a constant description of his traumas, shows. Identifying with the discourse of illness or trauma and building on the identity of the vulnerable, helpless victim may be a better outcome than the internalisation of negative attributes. However, in this case, service users tend to perceive themselves as having a very restricted possibility to act in the 
world. Victimisation is countered in stories that reinforce agency and 'voice'. Acting in response to perceived injustices, trying to improve mental health services and treatments, sharing their views with the public to raise awareness and fight stigmatisation are all forms of assuming an active position towards their own social status:

I was starting to ... all these questions came up in my mind about what had been happening, what had happened to me and I wanted to do something about it. [...] I thought that wasn't a good way that I was treated, that didn't help, and I wanted to be able to say something about it. (Marianne)

Identity seems to be also affected by the movement's leaders, local or national, people who carved out the service user role with their pioneering actions. Successful service users - whether accomplished researchers or local group facilitators - provide examples to their peers of how far service users are able to go:

I count myself really fortunate to have, very early on my career, been able to meet Diana Rose or Peter Beresford [...] Seeing those people and being kind of involved with those people has been amazingly important for me [...] Because I could see these really well-respected people, who had very very good academic careers, were very open, and their work was very valued, based on their experiences, based on their activism as well. (Valerie)

As role models, they allow service users not only to believe that they can recover, but also that their mental distress is compatible with accomplishments in private and public life, thus allowing them to reshape their own identities.

\section{Discussion}

Participants spoke of the hardness and difficulty of living with mental distress, which is only increased by the distress produced by stigmatisation, discrimination and the taboo that surrounds mental illness in society.

Engagement appears to provide some positive effects to mental health and recovery, many of which are related to its self-help element. In a safe environment of peers, service users/survivors feel accepted and find it easier to share their difficulties and troubles, which in turn helps them make sense of previously rejected experiences. Participants' discourses reinforce the benefits of self-help and mutual support found in the literature, such as reduction of social isolation, a sense of community, feelings of acceptance and understanding, assuming a valued role, learning coping strategies and encountering successful role models (Davidson et al., 1999).

For some participants, involvement was a stepping-stone for other achievements, and their interactions expanded beyond the movement. Others, however, had their relationships restricted to a circle of service users and mental health professionals. It is difficult to say how much of this limitation is a choice (as these are individuals who are strongly committed to the mental health cause) or a ghettoisation effect, as fear of widespread stigma leaves few possibilities for inclusion in non-mental health related communities. This is an aspect that may deserve further investigation in research. 
It is interesting to notice that self-help provides not only emotional support to overcome mental health problems, but also to overcome the distress produced by political action. As survivors feel disappointed with the results of their activism or troubled by confrontation with antagonists, political engagement can prove to be an emotionally high-cost activity, sometimes detrimental to recovery. Peer support helped participants to follow through with their activism and involvement, despite these obstacles. Self-help then emerges as an important element of the service user/survivor movement, promoting recovery through some level of social inclusion and sustaining engagement in the face of adversity.

Another aspect of the movement that impacts the experience of mental distress and recovery is the centrality of experience to political action in this social movement. The claim that first-hand experience of mental distress provides a special insight or knowledge is the very basis of mental health service user/survivor movements worldwide (Tomes, 2006). In fact, it is a central feature of a type of health social movement in which the experience of illness or bodily events defines the movement's identity and practices, being the basis that allows activists to politically challenge medical and scientific knowledge - what Brown et al. (2004) have called 'embodied health movements'. These movements may help to reshape personal experiences of a certain illness through changes in the regime of discourses, practices, identities and policies that constitute the experience of having that disease (Klawiter, 2004).

Experiential knowledge is central to the legitimacy of the survivor voice to challenge established notions of mental illness and professional practices in psychiatry (Noorani, 2013). Reframing mental distress as experiential knowledge transforms its meaning: from a hidden, shameful private experience, it becomes the basis of the collective action that takes place in the movement. The personal experience of mental distress is then used constructively to inform survivors' actions and agenda, strengthen collective identity between peers and support the movement's legitimacy. For some participants, this is lived as a reconfiguration of meaning at a personal level, as mental distress is recognised as an experience that is at least partially positive and valuable.

Political ideology has also been shown to be relevant in our analysis. Early on, the movement strongly opposed psychiatry, but radicalism was diluted throughout the decades, and opposition to the biomedical model or to forced treatment has become a controversial issue (Wallcraft et al., 2003). This heterogeneity, it seems, has some positive effects in terms of service users making sense of their experiences: those who question the biomedical model feel validated by the alternative explanations sustained by their peers; those who do not necessarily disagree with current views and practices in mental health find in service user groups repositories of information where they learn about diagnoses, drugs and other therapies, in a process that can be empowering and helpful to recovery.

Politically minded survivors, however, seem to experience more intensely a process of 'stigma conversion'. Stigma can be internalised when negative stereotypes are believed to be accurate and are incorporated into the person's identity, producing a number of negative outcomes (Ritsher and Phelan, 2004; Watson et al., 2007). Humphreys (cited by Herman and Musolf, 1998) called 'stigma conversion' the process in which stigmatised groups reverse internalised stigma, as they cease to attribute stigma to 
personal failings, and recognise them as societal problems. Corrigan and Watson (2002) found that stigmatised individuals who do not recognise the legitimacy of stigma and who share a group identity with the stigmatised group will turn their negative feelings towards the stigmatising group and feel 'righteously angry'.

At some point in their activist careers, some participants became aware of the social impediments that increase mental distress, such as social discrimination, prejudice or the iatrogenic effects of psychiatric treatments. This recognition allowed them to challenge the stereotypes attributed to the 'mentally ill' and to reframe stigmatic experiences, while serving as a motivation to get further involved and collectively transform reality. Engagement, then, helped reconstruct spoiled identities, as they began to see themselves as fighters and agents of social change. In this process, service user/survivor leaders serve as role models that attest the possibility of successfully integrating the experience of mental distress to a public identity, shedding the atmosphere of secrecy that surrounds mental illness.

Paradoxically, identity can also be an obstacle to succeed in the movement. The collective identity of the service user/survivor is not distinguished by a clear mark, such as a bodily event or a definite ideology, but by a very heterogeneous, personal experience. Perhaps as a response to this fluidity, some groups confer legitimacy only to members with certain characteristics, promoting exclusion instead of inclusion. This pressure within the movement can make survivors feel criticised and rejected when they fail to fit a certain standard or to follow certain implicit principles and norms.

User involvement is another aspect of the service user/survivor movement that seems to have ambiguous effects. As the shift in policy measures towards user involvement created a market for the experiential knowledge of service users, more and more survivors found themselves making careers out of their service user status, either as consultants or as hired workers. Expanding employment opportunities is an important aspect of promoting recovery, as unemployment is a recognised impairment to mental health (Paul and Moser, 2009) and access to employment is still a major issue for people with mental distress. This is attested by our research, as most participants had already been paid to work as service users and recognised the importance of this employment to their wellbeing. They valued the possibility of contributing socially and supporting themselves without having to hide previous experiences.

Some authors, however, have pointed out that user involvement has diverted activists from voluntary political action (Crossley, 2006), undermining the movement's cohesiveness and oppositional force (Pilgrim, 2012). Additionally, getting involved in participatory forums, committees and trusts can be very frustrating for service users, as restrictions to their power are continuously enforced (Barnes and Bowl, 2001; Lewis, 2014). Participants of this study reported patronising and confrontational attitudes from health professionals and government representatives, sensing that their participation was often tokenistic. If service users' contributions remain unheard, user involvement can be more disempowering than empowering, merely reinforcing the limits to what they can achieve.

\section{Concluding remarks}

As a result of an exploratory study with a sample of 12 service users/survivors, these findings should not be generalised, but taken as indications for future research. This 
study indicates that the British service user/survivor movement has some interconnected elements, such as self-help, user involvement and political activism, that impact differently on the experience of mental distress and recovery. Personal and collective identity emerged as important features to understand transformations in experience after involvement, as a certain level of identity reconstruction may take place in some cases, promoting the conversion of internalised stigma that can be detrimental to mental health. Transformations in the meaning of mental distress are another interesting topic to be researched: finding value in the experience of mental distress can be a form of improving self-esteem and integrating past experiences, or can lead to a difficulty letting go of rewarding states, such as manic episodes? (see Veseth et al., 2011). The scope and limits of social inclusion are other important topics to be further investigated, as taking part in the movement provides some social opportunities for the people involved, but also inserts them in conflictive relations that can be somewhat troubling and detrimental.

As the British service user/survivor movement and other health social movements gain relevance in the various fields of contention that involve health and disease, and as experience and recovery are at the centre of this kind of collective action, it becomes more important to understand the new forms of experiencing, surviving and recovering from health conditions that are being promoted and produced by their actions. Our preliminary findings indicate that involvement with the movement may promote recovery when this involvement helps to overcome some forms of invalidation: reversing internalised stigma, countering isolation, challenging established meanings for distress, providing positive role models and offering new and valued roles that integrate previous experience. Overall, these effects may reinforce one's personal journey of recovery, helping individuals find hope, support and meaning for their lives. Moreover, it promotes a form of recovery that is not professionally or individually oriented, but one that encompasses collaboration and the collective achievement of improved social conditions.

This does not mean, however, that involvement in this social movement should be seen as a form of therapy, which would be a perversion of the goals of social movements. We agree with Chamberlin (1978) when she argues that the process of consciousnessraising differs from therapy, as it does not aim to adjust individuals to a given reality, but to help them see how their problems are responses to real frustrations. Social movements should not be instrumentalised as therapy, although they may have beneficial consequences for the individuals engaged with them - Judi Chamberlin is one who has thoroughly recognised these consequences. Getting involved with a social movement is a transforming experience, even though this transformation is certainly a 'side-effect' of the movement's greater aim of social change.

\section{Funding}

This research received no specific grant from any funding agency in the public, commercial or not-for-profit sectors.

\section{References}

Archibald ME (2007) The Evolution of Self-Help - How a Health Movement Became an Institution. Basingstoke: Palgrave Macmillan. 
Barnes M and Bowl R (2001) Taking Over the Asylum - Empowerment and Mental Health. London: Palgrave Macmillan.

Bogdan RC and Biklen SK (1998) Qualitative research in education. An introduction to theory and methods. Boston: Allyn \& Bacon.

Borg M, Karlsson B, Lofthus A-M, et al. (2011) 'Hitting the wall': Lived experiences of mental health crises. International Journal of Qualitative Studies on Health and Well-Being 6(4): $1-9$.

Braun V and Clarke V (2006) Using thematic analysis in psychology. Qualitative Research in Psychology 3(2): 77-101.

Brown P, Zavestoski S, McCormick S, et al. (2004) Embodied health movements: New approaches to social movements in health. Sociology of Health \& Illness 26(1): 50-80.

Campbell P (2005) From little acorns - The mental health service user movement. In: Bell A and Lindley P (eds) Beyond the Water Towers - The Unfinished Revolution in Mental Health Services 1985-2005. London: The Sainsbury Centre for Mental Health, pp. 73-83.

Chadwick PK (2007) Peer-professional first-person account: Schizophrenia from the inside. Phenomenology and the integration of causes and meanings. Schizophrenia Bulletin 33(1): 166-173.

Chamberlin J (1978) On Our Own: Patient-Controlled Alternatives to the Mental Health System. New York: Hawthorne.

Charmaz K (2006) Constructing Grounded Theory: A Practical Guide through Qualitative Analysis. London: SAGE.

Corrigan PW and Watson AC (2002) The paradox of self-stigma and mental illness. Clinical Psychology: Science and Practice 9: 35-53.

Crossley N (2006) Contesting Psychiatry. London and New York: Routledge.

Davidson L and Roe D (2007) Recovery from versus recovery in serious mental illness: One strategy for lessening confusion plaguing recovery. Journal of Mental Health 16(4): 459-470.

Davidson L, Bellamy C, Guy K, et al. (2012) Peer support among persons with severe mental illnesses: A review of evidence and experience. World Psychiatry 11: 123-128.

Davidson L, Chinman M, Kloos B, et al. (1999) Peer support among individuals with severe mental illness: A review of the evidence. Clinical Psychology: Science and Practice 6(2): 165-187.

Deegan PE (1988) Recovery: The lived experience of rehabilitation. Psychosocial Rehabilitation Journal 9(4): 11-19.

Della Porta D and Diani M (1999) Social Movements - An Introduction. Oxford: Blackwell Publishing.

Herman N and Musolf GR (1998) Resistance among ex-psychiatric patients - Expressive and instrumental rituals. Journal of Contemporary Ethnography 26(4): 426-449.

Hutchinson A and Lovell A (2013) Participatory action research: moving beyond the mental health 'service user' identity. Journal of Psychiatric and Mental Health Nursing, 20: 641-649

Klawiter M (2004) Breast cancer in two regimes: The impact of social movements on illness experience. Sociology of Health \& Illness 26(6): 845-874.

Lewis L (2014) User involvement in mental health services: a case of power over discourse. Sociological Research Online, 19 (1) 6:1-15.

Moran GS, Russinova Z, Gidugu V, et al. (2012) Benefits and mechanisms of recovery among peer providers with psychiatric illnesses. Qualitative Health Research 22(3): 304-319.

Nelson G, Lord J and Ochocka J (2001) Empowerment and mental health in community: Narratives of psychiatric consumer/survivors. Journal of Community \& Applied Social Psychology 11(2): 125-142.

Noorani T (2013) Service user involvement, authority and the 'expert-by-experience' in mental health. Journal of Political Power 6(1): 49-68. 
Paul KI and Moser K (2009) Unemployment impairs mental health: Meta-analyses. Journal of Vocational Behavior 74: 264-282.

Pilgrim D (2008) 'Recovery’ and current mental health policy. Chronic Illness 4: 295-304.

Pilgrim D (2012) The British welfare state and mental health problems: The continuing relevance of the work of Claus Offe. Sociology of Health \& Illness 34(7): 1070-1084.

Pistrang N, Barker C and Humphreys K (2010) The contributions of mutual help groups for mental health problems to psychological well-being: A systematic review. In: Brown LD and Wituk S (eds) Mental Health Self-Help - Consumer and Family Initiatives. New York: Springer, pp. 71-86.

Ritsher JB and Phelan JC (2004) Internalized stigma predicts erosion of morale among psychiatric outpatients. Psychiatry Research 129: 257-265.

Rogers A and Pilgrim D (1991) 'Pulling down churches': Accounting for the British Mental Health Users' Movement. Sociology of Health \& Illness 13(2): 129-148.

Rogers A and Pilgrim D (2005) A Sociology of Mental Health and Illness. Berkshire: Open University Press.

Rose D and Beresford P (2009) Introduction. In: Sweeney A, Beresford P, Faulkner A, et al. (eds) This is Survivor Research. Ross-on-Wye: PCCS Books, pp.3-10.

Streubert HJ and Carpenter DR (2011) Qualitative Research in Nursing: Advancing the Humanistic Imperative. Philadelphia, PA: Lippincott Williams \& Wilkins.

Sweeney A, Beresford P, Faulkner A, et al. (2009) This is Survivor Research. Ross-on-Wye: PCSS Books.

Tomes N (2006) The patient as a policy factor: A historical case study of the consumer/survivor movement in mental health. Health Affairs 25(3): 720-729.

Topor A, Borg M, Di Girolamo S, et al. (2009) Not just an individual journey: Social aspects of recovery. International Journal of Social Psychiatry 57(1): 90-99.

Turner-Crowson J and Wallcraft J (2002) The recovery vision for mental health services and research: A British perspective. Psychiatric Rehabilitation Journal 25(3): 245-254.

Veseth M, Binder P-E, Borg M, et al. (2011) Toward caring for oneself in a life of intense ups and downs: A reflexive-collaborative exploration of recovery in bipolar disorder. Qualitative Health Research 22(1): 119-133.

Walker G and Bryant W (2013) Peer support in adult mental health services: A metasynthesis of qualitative findings. Psychiatric Rehabilitation Journal 36(1): 28-34.

Wallcraft J, Read J and Sweeney A (2003) On Our Own Terms: Users and Survivors of Mental Health Services Working Together for Support and Change. London: The Sainsbury Centre for Mental Health.

Watson AC, Corrigan P, Larson JE, et al. (2007) Self-stigma in people with mental illness. Schizophrenia Bulletin 33(6): 1312-1318.

\section{Author biographies}

Felismina Mendes is currently a professor of Sociology and Nursing at the University of Évora and a researcher for the Centre for Research and Studies in Sociology, University Institute of Lisbon (CIES-IUL). She earned her PhD in Sociology from the CIES-IUL. Her fields of interest are sociology of health and illness, namely, the biomedicalisation process and community health.

Carolina S Chassot is a PhD student in Social Psychology at the Federal University of Rio Grande do Sul, Brazil (UFRGS). She carried out her Master studies in Dynamics of Health and Welfare at the Erasmus Mundus Phoenix EM Consortium, offered jointly by the University of Évora (Portugal) and the École des Hautes Études en Sciences Sociales (France). Her fields of interest are public health, mental health, participatory processes, patient protagonism and social movements. 